\title{
Examining the Impact of Add-on Product Features as an Inferential Cue \\ Mark Anderson*
}

Kingston University, Kingston, Surrey, United Kingdom

\begin{abstract}
In many technology-based and service industries, firms offer "add-on" products to consumers who are purchasing (or have already purchased) a base product. For instance, electronic retailers usually offer a wide range of accessories (e.g. carrying cases, memory cards, keyboards, lenses) to consumers who purchase digital cameras or notebook computers. In the airline industry, service add-ons often include additional baggage allowance, alcoholic beverages, movies and gaming consoles, often sold separately.
\end{abstract}

Keywords: Industries; Service; Product; Digital cameras; Baggage; Keyboards

\section{Introduction}

Numerous studies have explored how product feature add-ons can be viewed as a way to discriminate on price [1-3], as a tool for greater customer customization [4] or creating switching costs, or as a means of segmenting markets [5]. Recent research by Bertini et al. [6] demonstrated that the mere availability of add-on features can also lead to significant changes in the perceived quality of a base good. The inferential effects of add-ons depended on whether the add-on features were alignable (in keeping with the core features of the product; e.g. cameras and add-on lenses) or non-alignable (different from the core features of the product; e.g. cameras and tripods, cameras and cases). Alignable add-ons were found to have a negative impact on the evaluation of the base good; nonalignables were found to improve the evaluation.

Despite these insights, questions remain regarding add-on features:

a) The Bertini et al. [6] study considered a 'high quality' base product only - would the impact of add-ons vary with the quality of the base product?

b) The previous study looked at alignable and non-alignable products separately. What is the impact on perceptions if both types of add-on are considered collectively?

The original study evaluated add-ons for digital cameras and PCs, using a U.S. sample. The current study looks at satellite navigation systems (SatNav) using a UK sample, with the information presented more closely reflecting typical online purchasing conditions (i.e. Amazon).

\section{Literature Review}

Research suggests that consumers often use peripheral cues to make inferences about a product's utility [7-9]. Research has shown that product attributes can compete and interact in consumer perception formation $[8,9]$, and where there is ambiguity, inferential biases or heuristics are applied [10], See Kardes, [11] for a review of consumer inference processes).

Until Bertini et al., [6] demonstrated that add-ons are used by consumers as inferential cues, such additions were mainly seen as price discriminators [12,13]. Ellison [1] considers add-ons as a typical price discrimination strategy, in which the base good, and the base good + add-on features, represent two distinct quality levels sold at different prices. In this scenario, add-ons are used by firms to discriminate between consumer groups. Add-ons within bundling strategies (where the add-on is part of a bundle of goods) encourage consumers to adopt inferential heuristics that decrease the cognitive effort of evaluating the offering [14].

Drawing on the established literature surrounding inference formation [15], Bertini, et al., [6] propose that, under certain conditions, consumers draw conclusions about the value of a base good (the focal object) from a firm's decision to supply one or more add-on features (the contextual cues). They look to the attribute-alignability literature [16-18] to develop their hypotheses. Under this theoretical lens, people perceive add-on products as either alignable (possessing common characteristics with the base product that enhance it, such as zoom lens for a digital camera) or non-alignable (no common characteristics and instead introducing new capabilities, such as a tripod or a carrying case for a camera). Previous research suggests that people seek to magnify the quantity of commonalities between options when making comparisons, suggesting that firms should focus on alignable over non-alignable differences, due to their increased salience [19] and easier comparison process for the consumer. In contrast, Bertini and colleagues argue that alignable add-ons shift consumer's reference level for the shared features (i.e. an attribute-level inference) and that nonalignable add-ons trigger an overall reassessment of product value by the consumer. Therefore, the presence of an alignable add-on will establish a higher 'range of attribute values that consumers then use to judge the performance of the base good'. This logic suggests the base good's performance level will be judged less favourably in the presence of an alignable add-on than it would be on its own. Conversely, for nonalignable add-ons the inference process is holistic, as there is no option to compare attributes. Without a natural frame of reference, consumer perceptions about the add-on product (assumed to be positive) will trigger a similar attitude towards the base product-'a halo effect'. Their results support this premise, finding that add-ons that introduced new features led participants to rate the base product more favourably. Add-ons that upgraded existing capabilities affected evaluations of the base product negatively. As predicted, these opposing effects waned when participants were given sufficient independent information (in the form of ratings) to judge the product on its own.

*Corresponding author: Mark Anderson, Kingston University, Kingston, Surrey United Kingdom, E-mail: m.anderson@kingston.ac.uk

Received March 06, 2015; Accepted March 11, 2015; Published March 18, 2015

Citation: Anderson M (2015) Examining the Impact of Add-on Product Features as an Inferential Cue. J Account Mark 4: 125. doi:10.4172/2168-9601.1000125

Copyright: (c) 2015 Anderson M. This is an open-access article distributed under the terms of the Creative Commons Attribution License, which permits unrestricted use, distribution, and reproduction in any medium, provided the original author and source are credited. 
Despite these findings, a number of questions remain. In the Bertini study, alignable and non-alignable add-ons were studied separately, however it is reasonable to assume that most products would offer both types of add-ons (e.g. digital cameras, computers, etc.). The overall effect of these opposing influences on the base product perception is unclear. In addition, the authors considered only the moderating effects of a positive independent review (presented as a rating of 8.5/10), finding that subjects exposed to this information no longer used the add-ons to form judgments. What would be the impact of a less positive rating? Following the general consensus that value functions are concave, a new feature should have a more positive contribution to an inferior product than a superior one [20]. Therefore, where product ratings are low, the impact of add-ons should be stronger. Finally, the previous research presented the base product and add-on information in a textbased format. However, an online or paper-based product promotion would typically contain pictures or graphics, as well as text. In line with calls for increased pragmatism and realism in marketing research [21], the current research attempts a more real-life presentation of a base product and add-ons.

\section{Aims and Objectives}

This study draws on the work of Bertini et al. [6] to explore the impact on a base product where an alignable and a non-alignable addon are both present. In specific we hypothesize:

H1: Where no other information is provided, a product will be less positively perceived when an alignable add-on is available as compared to when no add-on option exists.

$\mathrm{H} 2$ : Where no other information is provided, a product will be more positively perceived when a nonalignable add on is available, as compared to when no add-on option exists.

The next hypothesis considers the simultaneous presence of alignable and nonalignable add-ons. Past research suggests that when the overlap between objects decreases, the direct comparisons between dimensions (as present in alignable add-ons) gives way to the more general holistic judgments (nonalignable add-ons). As information demands increase, individuals act to reduce their cognitive load. For this reason, we anticipate the summary effect of an alignable and nonalignable add-on to favour the nonalignable add-on and deliver a favourable base product evaluation. Applying the same logic, we would expect two nonalignable products to have a more positive impact on the base product than an alignable + nonalignable add-on configuration. Therefore we hypothesize:

H3a: Where no other information is provided, the presence of both alignable and nonalignable add-ons will result in a more positively perceived base product than when no-adds options are present.

H3b: Where no other information is provided, the presence of two nonalignable add-ons will yield a more positively perceived base product than one alignable and one nonalignable add-on.

Finally the impact of add-on features where the product is perceived as lower quality (vs higher quality) will also be examined. We hypothesize:

$\mathrm{H} 4$ : The positive impact of add-on features will be greater for goods perceived as inferior (low quality) than for goods perceived as superior (high quality).

\section{Design and Participants}

The objective of the research is to test the hypotheses above.
Using an online survey, participants viewed information about a new satellite navigation ('satnav') product, and then answered a series of questions related to the product. Two separate studies were conducted Respondents were recruited via a UK online consumer panel. The stimulus presented to respondents showed a photo of a satnav with corresponding product features (attribute information). The overall product presentation was in a style similar to that found on UK shopping websites at the time, such as Amazon, Halfords, Argos and PCWorld. Both the satnav product and features displayed were selected on the basis of a pretest with a separate sample.

The experiments used a between subjects factorial design. In the first study ( $\mathrm{n}=157)$, add-on type was manipulated across five (5) levels. In the control condition there was no mention of add-on features. In the subsequent 3 treatment conditions, participants are offered either: i) an alignable add-on (a micro SD memory card); ii) a nonalignable add-on (a suction cup mount); iii) the alignable and nonalignable addon together; or iv) two nonalignable add-ons together. The stimulus clearly state that the add-ons were offered separately and could only be purchased at an extra cost. The second study used a 3 (add-on type) $\times$ 3 (product information) experimental design. In the control condition there were no add-ons; in the treatment condition participants were offered either the alignable add on or the non-alignable one. We manipulated the second factor, product information, across three levels. The control group received no additional information about the product The treatment groups were presented with either low (50\%) or high (90\%) quality rating by experts at Satnatreviews.co.uk (a fictitious source). Figure 1 shows the base product presentation.

After reviewing the product, participants evaluated the satnav using three 10 -point slider scales: perceived quality $(0=$ very low quality, $10=$ very high quality), probability of liking the product $(0=$ not at all, $10=$ very high $)$ and fit with personal needs $(0=$ very poor, $10=$ very good) (Figure 1).

\section{Results}

We first conducted a reliability analysis of the three product evaluation questions indicated that these scales were sufficiently correlated to collapse into one overall assessment of the base product (Cronbach Alpha $=.846)$. For study $1(\mathrm{n}=153)$, we analysed the aggregate preference measure against the 5 add-on conditions using betweensubjects ANOVA. We observe a main effect of add-on type $(\mathrm{F}(4,152)=$ $\left.17.304, \mathrm{p}=.000, \mathrm{\eta}^{2}=.313\right)$, revealing significant differences in the mean

\section{SATELLITE NAVIGATION 2081AS}

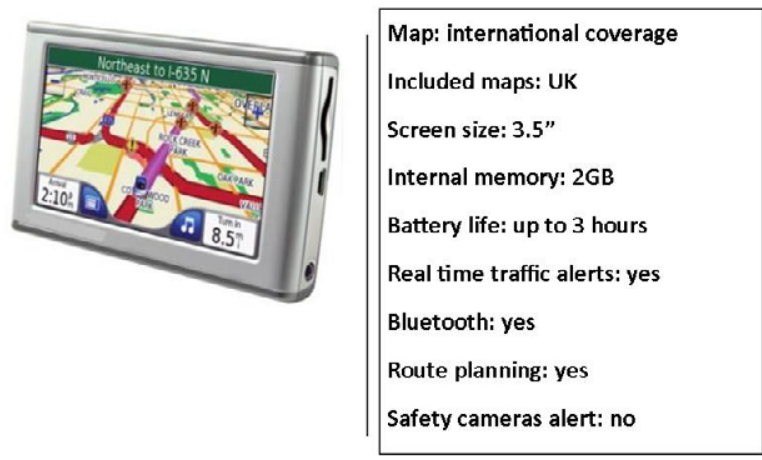

Figure 1: SatNav base product. 
values for the product under the different add-on scenarios. As can be seen from Figure 2, there was a rise in the base product evaluation when an add-on was available, with the perceived utility of the satnav at its lowest when there are no add-ons (mean=3.91), rising with an alignable add-on (mean=5.95) and with an nonalignable add-on $($ mean $=6.23)$. Interestingly, both alignable and nonalignable add-ons increased the perceived attractiveness of the base product, in contrast to the findings of Bernini et al., [6]. Planned contrasts (t-tests) pitted the control condition against each treatment condition, highlighting that the observed increases in base product evaluations were significant for the alignable add-on $(\mathrm{t}(152)=-2.68, \mathrm{p}=.008)$ and nonalignable addon $(\mathrm{t}(152)=-2.509, \mathrm{p}=.013)$. The presence of both an alignable and nonalignable add-on together further increased product evaluations (mean $=6.54 ; \mathrm{t}(152)=-2.700, \mathrm{p}=.009$ ), although this increase was not significantly different than for a single add-on $(\mathrm{t}(152)=-.903, \mathrm{p}=.372)$. Hence, $\mathrm{H} 2$ is supported but $\mathrm{H} 1$ is rejected. $\mathrm{H} 3 \mathrm{a}$ is supported. We find the two nonalignable add-ons deliver a higher base product evaluation $(\mathrm{M}=6.75)$ than the mixed alignability offering, but this difference is not significant $(\mathrm{t}(152)=.-507, \mathrm{p}=.614)$, so $\mathrm{H} 3 \mathrm{~b}$ is rejected (Figure 2$)$.

In the second study ( $\mathrm{n}=275)$, we analysed product evaluation using a 3 (no add-on, an alignable add-on, non-alignable add-on) $\times 3$ (no product quality information, low quality rating, high quality rating) between-subjects ANOVA. We observed a main effect of add-on type $\left(\mathrm{F}(2,240)=21.987, \mathrm{p}=.000, \eta^{2}=.155\right)$ and product information $(\mathrm{F}(2$, $240)=15.143, \mathrm{p}=.000, \eta^{2}=.112$ ). More importantly we found interaction effects between these factors $\left(F(4,240)=9.731, p=.000, \eta^{2}=.140\right)$. Mean responses across conditions are displayed in Figure 3.

To test H4, we again use planned contrasts (t-tests) to look at the individual relationships. An add-on has a significant positive effect on product evaluations where there is either no product information $(\mathrm{t}(78)$ $=8.948, \mathrm{p}=.000)$ or negative product information is provided $(\mathrm{t}(60)=$ $-5.83, \mathrm{p}=0.000$ ). Looking at Figure 2, we can see that where the product information is positive, the presence of add-ons (either alignable or nonalignable) decreases the product evaluation slightly, although this difference is not significant $(\mathrm{t}(67)=.677, \mathrm{p}=.501)$. Therefore, we conclude that add-ons have a more positive influence on products with a lower quality perception than for products with a higher quality perception, supporting H4 (Figure 3).

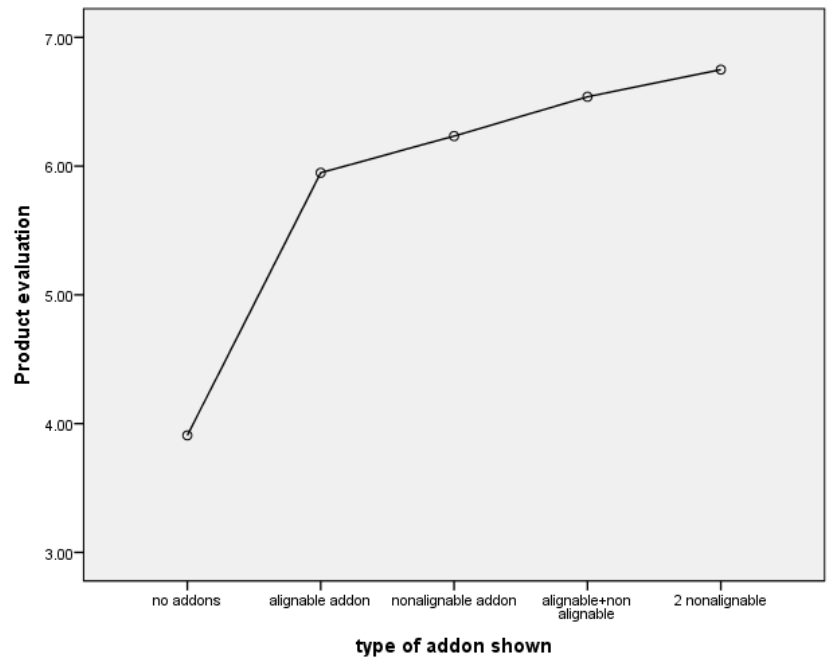

Figure 2: Product Evaluation.

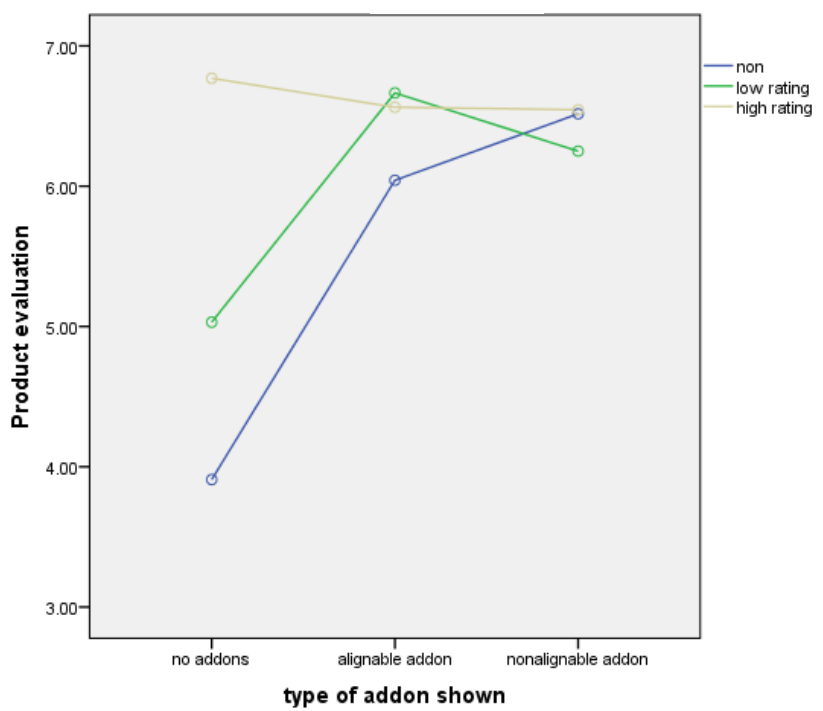

Figure 3: Graph of Product Evaluation and type of addon shown.

\section{Discussion and Limitations}

The results of these studies lend support to the notion that the availability of add-ons influences an individual's view of a base product. Our results confirm that add-ons are a valuable tool for differentiation with consumer's where little additional information is available. Indeed the results suggest where available information indicates the product is of inferior (or at least not superior) quality, the presence of add-ons provide reassurance to the consumer, acting to 'balance out' a negative external rating. However, the findings indicate that consumers do not perceive alignable and nonalignable add-ons to be different. The mere availability of an additional, discretionary option for a product is sufficient to shift perceptions, but only where there is little or negative product information available. In considering why alignable differences might not result in a lower product evaluation (as found in previous research), we believe that the performance of a base good attribute is not necessarily judged less favourably when an optional higher performing version of the attribute is available. Although range theory [22] supports the premise of a negatively adjusted evaluation for alignable add-ons, an alternate proposition can be found in the literature on mass customization [23]. The availability of add-ons allows for a degree of customization of the end product, which has been associated with increased customer value perceptions and willingness-to-pay [24]. The availability of an alignable add-on encourages the customer to determine whether the base product attribute is fit for purpose, and may increase feelings of performance rather than diminish them. With little difference between evaluations for alignable and nonalignable add-ons, the results suggest that consumers are considering the base product as one they can customize as needed. The increase in product evaluation where two add-ons are present supports the notion that customization potential is a driver of customer perceptions, rather than range effects. The results suggest that offering a range of discretionary add-ons may be a useful strategy for weaker competitors, but is of limited benefit for stronger (i.e. superior quality) players $[25,26]$.

A number of limitations exist with the study. Although the product was presented with graphics and text to resemble an online retail format, there was no scope for considering a competitive setting. 
Citation: Anderson M (2015) Examining the Impact of Add-on Product Features as an Inferential Cue. J Account Mark 4: 125. doi:10.4172/21689601.1000125

Future research could look at the impact of competitive offerings on consumers' perceptions in an online shopping context. For instance, how do rival add-ons affect customer inferences of a product? How do add-ons effect perceptions where products are at different price points? In addition, the current studies considered the impact on quality perceptions only; future research could look at the impact on purchase intentions and/or willingness-to-pay. Further research could also consider the impact of add-on type, valence, competitive context and pricing to clarify strategies for product differentiation.

\section{References}

1. Ellison G (2005) A Model of Add-on Pricing. Quarterly Journal of Economics 120: 595-637.

2. Erat S, Bhaskarahn S (2012) Consumer Mental Accounting: Implications to Selling Base Products and Add-ons. Marketing Science 31: 801-818.

3. Gabaix X, Laibson D (2006) Shrouded Attributes, Consumer Myopia, and Information Suppression in Competitive Markets. The Quarterly Journal of Economics 121: 505-540.

4. Bayus B, Putsis W (1999) Product proliferation: An empirical analysis of product line determinants and market outcomes. Marketing Science 18: 137-153.

5. Hoch S, Bradlow E, Wansink B (1999) The Variety of an Assortment. Marketing Science 18: 527-546.

6. Bertini M, Ofek E, Ariely D (2009) The Impact of Add-On Features on Consumer Product Evaluations. Journal of Consumer Research 36: 17-28.

7. Bettman J, Luce M, Payne J (1998) Constructive Consumer Choice Processes. Journal of Consumer Research, 25: 187-217.

8. Broniarczyk S, Alba J (1994) The importance of the brand in brand extension. Journal of Marketing Research 31: 214-228.

9. Tversky A, Simonson I (1993) Context-Dependent Preferences. Management Science 39: 1179-1189.

10. Van Osselaer S, Alba J (2000) Consumer Learning and Brand Equity. Journal of Consumer Research 27: 1-16.

11. Van Osselaer S, Janiszewski C (2001) Two Ways of Learning Brand Associations. Journal of Consumer Research 28: 202-223.
12. Noseworthy T, Wang J, Islam T (2012) How Context Shapes Category Inferences and Attribute Preference for New Ambiguous Products. Journal of Consumer Psychology 22: 529-544.

13. Kardes F (2013) Selective Versus Comparative Processing. Journal of Consumer Psychology 23: 150-153.

14. Guiltinan J (1987) The Price Bundling of Services: A Normative Framework. Journal of Marketing 51: 74-85.

15. Chakravarti D, Greenleaf E, Sinha A, Cheema A, Cox J, et al. (2002) Auctions Research Opportunities in Marketing. Marketing Letters 13: 281-296.

16. Ahmetoglu G, Furnham A, Fagan P (2014) Pricing practices: A critical review of their effects on consumer perceptions and behaviour. Journal of Retailing and Consumer Services 21: 696-707.

17. Ariely G, Loewenstein G, Prelec D (2003) Coherent Arbitrariness: Stable demand curves without stable preferences. The Quarterly Journal of Economics 118: $73-116$

18. Markman A, Medin D (1995) Similarity and alignment in choice. Organizational Behavior and Human Decision Processes 63: 117-130.

19. Okada E (2006) Upgrades and New Purchases. Journal of Marketing 70: 92-102.

20. Zhang S, Markman A (2001) Processing product unique features: Alignability and involvement in preference construction. Journal of Consumer Psychology 11: $13-27$.

21. Zhang S, Markman A (1998) Overcoming the early entrant advantage: The role of alignable and nonalignable differences. Journal of Marketing Research 35: 413-426.

22. Nowlis S, Simonson I (1996) The Effect of New Product Features on Brand Choice. Journal of Marketing Research 33: 36-46.

23. Meyer R, Paul Green (2013) The Challenges Facing Marketing. Journal of Marketing Research 50: 1-2.

24. Janiszewski C, Lichenstein DR (1999) A range theory account of price perception. Journal of Consumer Research 25: 353-368.

25. Franke N, Screier M (2002) Entrepreneurial Opportunities with Toolkits for User Innovation and Design. The International Journal on Media Management 4 239-248.

26. Schreier M (2006) The value increment of mass-customized products: an empirical assessment. Journal of Consumer Behaviour 5: 317-327. 